\title{
Prolyl-4-hydroxylase 2 enhances hypoxia-induced glioblastoma cell death by regulating the gene expression of hypoxia-inducible factor- $\alpha$
}

\author{
W Sun ${ }^{\star, 1}$, W Jelkmann ${ }^{1}$ and R Depping ${ }^{1}$
}

Oxygen deprivation (hypoxia) is a common feature of solid tumors in advanced stages. The primary cellular transcriptional responses to hypoxia are mainly mediated by the transcription factor hypoxia-inducible factor (HIF). HIF consists of an oxygenlabile $\alpha$-subunit (HIF-1 $\alpha,-2 \alpha$ ) and a stable $\beta$-subunit (ARNT). Prolyl-4-hydroxylase 2 (PHD2) is known as an important mediator of the oxygen-dependent degradation of HIF- $\alpha$ subunits. As HIF- $\alpha$ subunits are not confirmed to be the only substrates of PHD2, it is unknown whether PHD2 regulates HIF-1 $\alpha$ and HIF-2 $\alpha$ by interacting with other intracellular molecules. In this study, we found that in the glioblastoma cells, PHD2 maintains the gene expression of HIF-1 $\alpha$ in dependence of nuclear factor $\kappa$ B and suppresses the gene expression of HIF-2 $\alpha$ through HIF-1 $\alpha$. The PHD2-mediated degradation of HIF-1 $\alpha$ and HIF-2 $\alpha$ seems less important. Furthermore, PHD2 enhances hypoxia-induced glioblastoma cell death by modulating the expression of the HIF target genes glucose transporter 1, vascular endothelial growth factor-A and Bcl-2 binding protein 3. Our findings show that PHD2 inhibits the adaptation of glioblastoma cells to hypoxia by regulating the HIF- $\alpha$ subunits in a non-canonical way. Modulation of PHD2 activity might be considered as a new way to inhibit glioblastoma progression.

Cell Death and Disease (2014) 5, e1322; doi:10.1038/cddis.2014.295; published online 10 July 2014

\section{Introduction}

Glioblastoma (Glioblastoma multiforme) is the most common and most aggressvie primary brain tumor in adults. ${ }^{1}$ Glioblastomas in advanced stages generally contain areas with oxygen deprivation (hypoxia) due to an imbalance between the tumor growth and the vascularization. ${ }^{2,3}$ The primary transcriptional responses of the glioblasotma cells to hypoxia are mainly mediated by the transcription factor hypoxiainducible factor (HIF). HIF is a heterodimer consisting of an oxygen-labile $\alpha$-subunit (HIF- $1 \alpha,-2 \alpha)$ and a stable $\beta$-subunit (ARNT). Both subunits belong to the basic Helix-Loop-Helix PER-ARNT-SIM (bHLH-PAS) family of transcription factors. HIF- $1 \alpha$ and HIF- $2 \alpha$ are rapidly degraded by the proteasome in the presence of oxygen. In hypoxia, the degradation of HIF-1 $\alpha$ and HIF-2 $\alpha$ is suppressed through various mechanisms. HIF- $1 \alpha$ and HIF- $2 \alpha$ are stabilized, form heterodimers with ARNT (HIF-1 $\alpha /$ ARNT, HIF-2 $\alpha / A R N T)$ and regulate the expression of a variety of genes by binding to the hypoxia-response elements. ${ }^{4,5}$

HIF- $1 \alpha$ and HIF- $2 \alpha$ affect many key aspects of glioblastoma progression including angiogenesis, glucose metabolism and apoptosis. ${ }^{6}$ Increased expression of HIF- $2 \alpha$ in glioblastoma tissues has been reported to be associated with poor prognosis. ${ }^{7}$ Therefore, HIF- $1 \alpha$ and HIF- $2 \alpha$ represent attractive targets for glioblastoma therapy.

The oxygen-dependent degradation of HIF- $1 \alpha$ and HIF- $2 \alpha$ is mainly mediated by the HIF-Prolyl-4-Hydroxylases (PHDs). PHDs are dioxygenases that require oxygen as a co-substrate.
HIF- $1 \alpha$ and HIF- $2 \alpha$ are hydroxylated by the PHDs at certain prolyl residues in the oxygen-dependent degradation domains and subsequently recognized by the von-Hippel-Lindau tumor suppressor protein ( $\mathrm{pVHL}$ ). $\mathrm{pVHL}$ is a part of a multicomponent E3-ligase ( $\mathrm{pVHL}$-elonginB-elonginC-Cul2-Rbx) and targets $\mathrm{HIF}-1 \alpha$ and HIF- $2 \alpha$ for proteasomal degradation. The rate of HIF prolyl hydroxylation is reduced in hypoxia, which enables HIF- $1 \alpha$ and HIF- $2 \alpha$ to accumulate to high levels. ${ }^{8}$

Four PHDs (PHD1-4) have been identified so far. All PHDs are able to hydroxylate HIF- $1 \alpha$ and HIF- $2 \alpha$ in vitro. ${ }^{8-10}$ However, the expression levels and the substrate preferences of the PHDs vary between tissues. ${ }^{11-14}$ Besides, the PHDs were discussed to regulate several HIF-independent pathways. ${ }^{15-21}$ It is unclear whether the PHDs regulate the steady-state levels of HIF- $1 \alpha$ and HIF- $2 \alpha$ by interacting with other intracellular molecules in glioblastoma cells.

In this study, we focused on the indirect regulation of HIF- $1 \alpha$ and HIF-2 $\alpha$ by Prolyl-4-hydroxylase 2 (PHD2) in glioblastoma cells. RNA interference studies showed that in three human glioblastoma cell lines, PHD2 oppositely regulates the gene expression of HIF- $1 \alpha$ and HIF- $2 \alpha$ by maintaining the synthesis of the $\mathrm{NF} \kappa \mathrm{B}$ subunit p50. PHD2 knockdown caused a significant downregulation of HIF- $1 \alpha$ expression and a marked reduction of HIF- $1 \alpha$ protein glioblastoma cells. The PHD2mediated proteasomal degradation of HIF- $1 \alpha$ seemed less important. The mRNA and the protein contents of HIF-2 $\alpha$ were elevated in the PHD2 knockdown cells due to the downregulation of HIF-1 $\alpha$ expression. Furthermore, PHD2 promotes

${ }^{1}$ Institute of Physiology, Center for Structural and Cell Biology in Medicine, University of Luebeck, Luebeck, Germany

*Corresponding author: W Sun, Institute of Physiology, Center for Structural and Cell Biology in Medicine, University of Luebeck, Ratzeburger Allee 160, 23562 Luebeck, Germany. Tel: +49 451500 4174; Fax: +49 451500 4151; E-mail: wenwen.sun@ medizin.uni-luebeck.de

Abbreviations: BNIP3, bcl-2 binding protein 3; GLUT, glucose transporter; HIF, hypoxia-inducible factor; NF $\kappa$ B, nuclear factor $\kappa$ B; PHD, HIF-prolyl-4-hydroxylase; VEGF, vascular endothelial growth factor.

Received 22.2.14; revised 30.5.14; accepted 03.6.14; Edited by C Munoz-Pinedo 
hypoxia-induced glioblastoma cell death by modulating the expression of the HIF target genes glucose transporter 1 (GLUT1), vascular endothelial growth factor-A (VEGF-A) and Bcl-binding protein 3 (BNIP3). Our findings show that PHD2 inhibits the adaptation of the glioblastoma cells to hypoxia by regulating the HIF- $\alpha$ subunits in a non-canonical way. Targeted modulation of PHD2 activity might be considered as new way to inhibit the progression of glioblastomas.

\section{Results}

PHD2 maintains the gene expression of HIF-1 $\alpha$ in glioblastoma cells. The glioblastoma cells were transfected with siRNA against PHD2. A sufficient PHD2 knockdown was achieved $24 \mathrm{~h}$ after transfection (Figure 1a). To study the role of PHD2 in regulating the steady-state level of $\mathrm{HIF}-1 \alpha$, the cells were incubated for $2 \mathrm{~h}$ in normoxia or hypoxia $\left(3 \% \mathrm{O}_{2}\right) 48 \mathrm{~h}$ after transfection. In all three glioblastoma cell lines, PHD2 knockdown caused a marked reduction of HIF- $1 \alpha$ in hypoxia. HIF- $1 \alpha$ was nearly undetectable in the normoxic cells. The influence of PHD2 on HIF-1 $\alpha$ protein in normoxia could therefore not be estimated (Figure 1b). Quantitative RT-PCR showed that the mRNA of HIF- $1 \alpha$ was significantly decreased in the PHD2 knockdown cells (Figure 1c).

PHD2 maintains the gene expression of the NF $\kappa \mathrm{B}$ subunit p50 in glioblastoma cells. To understand how $\mathrm{PHD} 2$ regulates the gene expression of $\mathrm{HIF}-1 \alpha$, we studied whether PHD2 influences the activity of nuclear factor $\kappa \mathrm{B}$ $(\mathrm{NF} \kappa \mathrm{B})$, a well-characterized regulator of HIF-1 $\alpha$ transcription. $\mathrm{NF}_{\kappa} \mathrm{B}$ is a dimeric transcription factor. The subunits p65 and p50 were reported to have the strongest binding affinity to the HIF-1 $\alpha$ promoter. ${ }^{22-24}$ We confirmed the binding of $p 65$ and p50 to the HIF-1 $\alpha$ promoter in the glioblastoma cells with chromatin immunoprecipitation (data not shown). As shown in Figure $2 \mathrm{a}$, the protein content of p50 in the PHD2 knockdown cells was markedly lower than in the control cells. The amount of p50 in nuclear extract was also decreased. The subcellular distribution of p50 seemed not to be affected, as the protein contents of p50 were almost evenly reduced in nucleus (by ca. 70\%) and cytoplasm (by ca. 60\%; Supplementary Figures S1B and C). Quantitative RT-PCR showed that the gene expression of p50 was reduced in the PHD2 knockdown cells (Figure $2 b$ ). The protein amount and the subcellular distribution of p65 were not changed in the PHD2 knockdown cells (Supplementary Figure $\mathrm{S} 1 \mathrm{~A})$. The transactivation activity of $\mathrm{NF} \kappa \mathrm{B}$ was consequently decreased in the PHD2 knockdown cells (Figure 2c).

PHD2 constitutively suppresses the gene expression of HIF-2 $\alpha$ through HIF-1 $\alpha$ in glioblastoma cells. It was reported that HIF- $1 \alpha$ suppresses the expression of HIF- $2 \alpha$ expression in different cell lines including glioblastoma cells. $^{25,26}$ Thus, we assumed that the expression of HIF- $2 \alpha$ might be increased in the PHD2 knockdown cells due to the downregulation of HIF- $1 \alpha$ expression. We first confirmed the regulation of HIF- $2 \alpha$ expression by HIF- $1 \alpha$ in the glioblastoma cells. HIF-1 $\alpha$ was knocked down with siRNA (Figure 3a). Forty-eight hours after transfection, the mRNA content of HIF-2 $\alpha$ was significantly elevated in all three glioblastoma cell lines (Figure 3b).

We then studied the influence of PHD2 knockdown on HIF-2 $\alpha$ gene expression. As shown in Figure 4a, the gene expression of HIF-2 $\alpha$ was significantly enhanced in the glioblastoma a
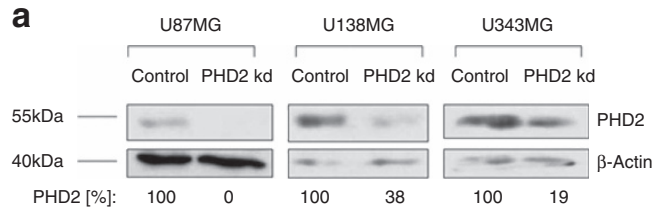

C

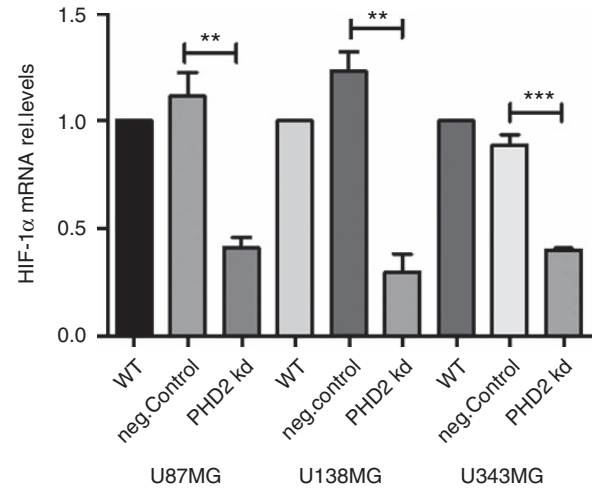

b
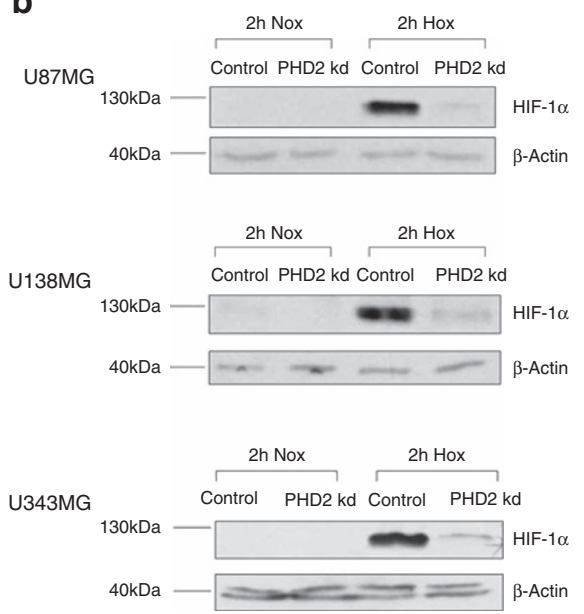

Figure 1 PHD2 maintains the gene expression of HIF-1 $\alpha$. U87MG, U138MG and U343MG cells were transfected with non-specific siRNA (Control) or siRNA against PHD2 (PHD2 kd). (a) Twenty-four hours after transfection, PHD2 was detected by immunoblotting. $\beta$-Actin was used as loading control. The results are representative for three independent experiments. (b) Forty-eight hours after transfection, cells were incubated for $2 \mathrm{~h}$ in normoxia $\left(20 \% \mathrm{O}_{2}\right)$ or hypoxia $\left(3 \% \mathrm{O}_{2}\right)$. HIF-1 $\alpha$ was detected by immunoblotting. $\beta$-Actin was used as loading control. The results are representative for three independent experiments. (c) U87MG, U138MG and U343MG cells were transfected with water (WT), non-specific siRNA (neg.Control) or siRNA against PHD2 (PHD2 kd). Forty-eight hours after transfection, total mRNA was analyzed for HIF-1 $\alpha$ and ribosomal protein L28 expression by qRT-PCR. Normalized HIF-1 $\alpha /$ L28 ratios are shown. The data are shown as the mean \pm S.E.M. $(n=3)$. ${ }^{* \star} P<0.01,{ }^{* * \star} P<0.001$ 
a
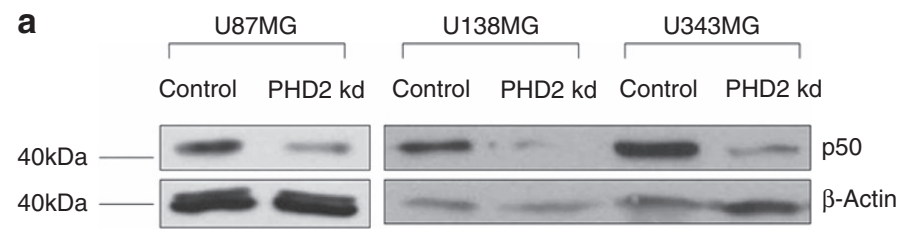

b

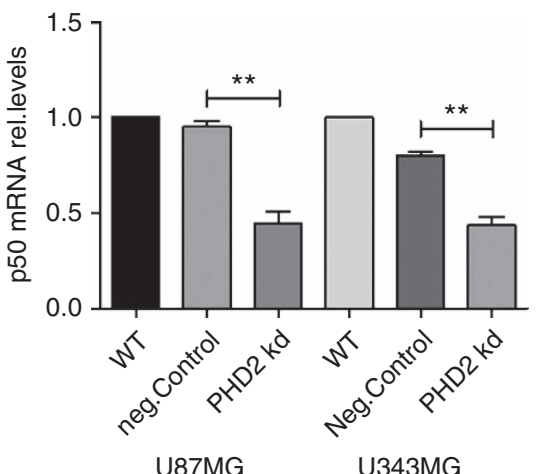

C

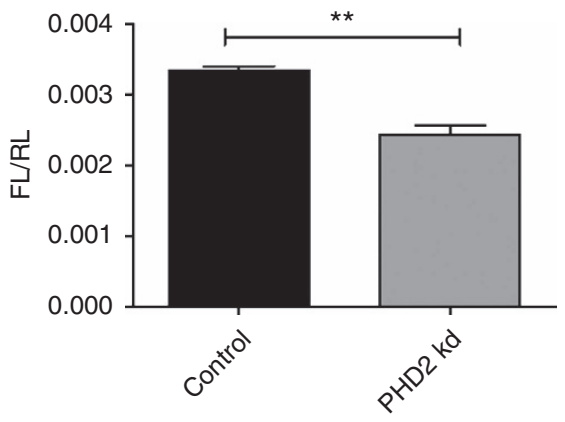

Figure 2 PHD2 maintains the basal activity of NF $\kappa$ B. (a) U87MG, U138MG and U343MG cells were transfected with non-specific siRNA (Control) or siRNA against PHD2 (PHD2 kd). Forty-eight hours after transfection, p50 was detected by immunoblotting. $\beta$-Actin was used as loading control. The results are representative for three independent experiments. (b) U87MG and U343MG cells were transfected with water (WT), non-specific siRNA (neg.Control) or siRNA against PHD2 (PHD2 kd). Forty-eight hours after transfection, total mRNA was analyzed for p50 and ribosomal protein L28 expression by qRT-PCR. Normalized p50/L28 ratios are shown. The data are shown as the mean \pm S.E.M. $(n=3)$. ${ }^{*} P<0.01$. (c) U87MG cells were co-transfected with NF $\kappa$ B responsive firefly luciferase plasmids and renilla luciferase plasmids. Six hours later, cells were transfected with siRNA against PHD2 and incubated further for $48 \mathrm{~h}$. Firefly luciferase activities (FL) were normalized to Renilla luciferase activities (RL). The data are shown as the mean \pm S.E.M. $(n=3) .{ }^{* *} P<0.01$

cells 48-72 $\mathrm{h}$ after PHD2 siRNA transfection (U87MG: $48 \mathrm{~h}$, U138MG: 72h). A marked increase in HIF-2 $\alpha$ protein level was also observed in the PHD2 knockdown cells (Figure 4b).

PHD2 modulates the expression of HIF target genes in glioblastoma cells. We further studied whether PHD2 affects the expression of the HIF target genes in hypoxic glioblastoma cells. Forty-eight hours after siRNA transfection, the cells were incubated for $24 \mathrm{~h}$ in hypoxia $\left(3 \% \mathrm{O}_{2}\right)$. The expression levels of three HIF target genes GLUT1, VEGF-A and BNIP3 were studied. As shown in Figure 5, the expression of GLUT1 (Figure 5a) and VEGF-A (Figure 5b) was significantly upregulated in the PHD2 knockdown cells. The gene expression of BNIP3 (Figure 5c) was decreased.

PHD2 enhances hypoxia-induced glioblastoma cell death. VEGF-A, GLUT1 and BNIP3 are central regulators of the cellular adaptation to hypoxia. ${ }^{27-31}$ VEGF-A was discussed to be cytoprotective independent of its angiogenic potential. $^{32-34}$ Thus, we further studied the influence of PHD2 on hypoxia-induced glioblastoma cell death. Fortyeight hours after siRNA transfection, the cells were incubated for $48 \mathrm{~h}$ in normoxia or hypoxia $\left(3 \% \mathrm{O}_{2}\right)$. The experiments were performed in absence of FCS to minimize cell proliferation. MTT (3-(4, 5-dimethylthiazol-2-yl)-2, 5-diphenyl tetrazolium bromide) assay showed that hypoxic incubation caused a viability reduction of the control cells by approximately 56\% (U87MG)/43\% (U138MG), whereas the viability of the PHD2 knockdown cells was only reduced by $25 \%$ (U87MG) /18\% (U138MG; Figure 6a).
We studied whether PHD2 promotes apoptotic glioblastoma cell death using DNA fragmentation ELISA. As shown in Figure $6 \mathrm{~b}$, the apoptosis of the hypoxic glioblastoma cells was not significantly affected by PHD2.

Exogenous PHD2 has no impact on the gene expression of HIF- $1 \alpha$ and HIF- $2 \alpha$ in glioblastoma cells. We attempted to study whether exogenous PHD2 has the opposite effect on HIF- $1 \alpha$ and HIF- $2 \alpha$ expression. The glioblastoma cells were transiently transfected with PHD2. The optimal transfection efficiency was achieved $24 \mathrm{~h}$ after transfection (Figure $7 \mathrm{a}$ ). Forty-eight hours after transfection, the mRNA contents of HIF- $1 \alpha$ and HIF-2 $\alpha$ were analyzed using qRT-PCR. As shown in Figures $7 b$ and $c$, the exogenous PHD2 had no significant impact on the gene expression of HIF- $1 \alpha$ and HIF- $2 \alpha$.

The influence of PHD2 knockdown on the gene expression of HIF- $1 \alpha$, HIF- $2 \alpha$ and p50 is not caused by off-target effect. To confirm that the influence of PHD2 knockdown on the gene expression of HIF- $1 \alpha$, HIF- $2 \alpha$ and p50 is not caused by the off-target effect of siRNA, we performed knockdown studies with an independent PHD2 siRNA (\#2). As shown in Supplementary Figure S2, the independent PHD2 siRNA had the same effect on the mRNA levels of HIF- $1 \alpha, \mathrm{HIF}-2 \alpha$ and p50 in glioblastoma cells.

PHD1 maintains the low level of HIF-1 $\alpha$ in normoxic glioblastoma cells. To determine whether the low level of HIF-1 $\alpha$ in normoxic glioblastoma cells is maintained by other PHDs, we studied the influence of PHD1 and PHD3 knockdown on the HIF-1 $\alpha$ protein level in normoxia. 


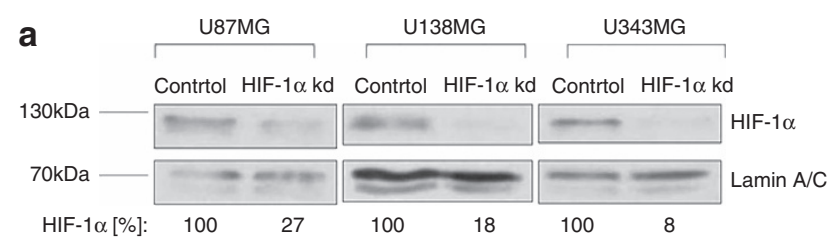

b

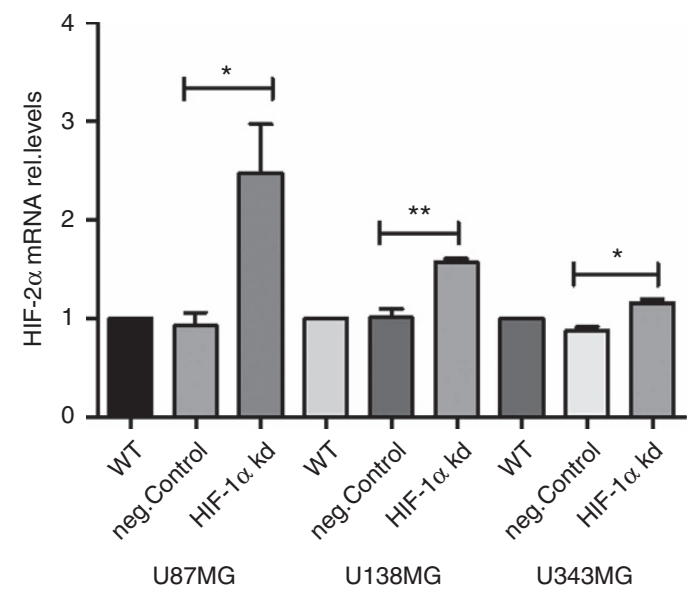

Figure $3 \mathrm{HIF}-1 \alpha$ suppresses the gene expression of HIF-2 $\alpha$. (a) U87MG, U138MG and U343MG cells were transfected with non-specific siRNA (Control) or siRNA against HIF- $1 \alpha$ (HIF-1 $\alpha$ kd). Forty-eight hours after transfection, cells were incubated for $2 \mathrm{~h}$ in hypoxia $\left(3 \% \mathrm{O}_{2}\right)$. HIF-1 $\alpha$ was detected by immunoblotting. $\beta$-Actin was used as loading control. The results are representative for three independent experiments. (b) U87MG, U138MG and U343 cells were transfected with water (WT), non-specific siRNA (neg.Control) or siRNA against HIF- $1 \alpha$ (HIF- $1 \alpha$ kd). Forty-eight hours after transfection, total mRNA was analyzed for HIF-2 $\alpha$ and ribosomal protein L28 expression by qRT-PCR. Normalized HIF-2 $\alpha /$ L28 ratios are shown. The data are shown as the mean \pm S.E.M. $(n=3) .{ }^{*} P<0.05,{ }^{* *} P<0.01$

According to Henze et al., ${ }^{11}$ the expression level of PHD4 in glioblastoma cells is much lower than other PHDs. It is therefore rather unlikely that PHD4 has a major role in maintaining the low level of HIF- $1 \alpha$.

As shown in Supplementary Figure S3, a knockdown of PHD1 led to an accumulation of HIF- $1 \alpha$ in normoxic glioblastoma cells. Hypoxic glioblastoma cell extracts were used as positive control. HIF- $1 \alpha$ did not accumulate in the PHD3 knockdown glioblastoma cells (Supplementary Figures S4A and B).

PHD3 expression is not upregulated in PHD2 knockdown glioblastoma cells. To investigate whether PHD3 is involved in the downregulation of HIF- $1 \alpha$ expression by PHD2, we studied the influence of PHD2 knockdown on the gene expression of PHD3 using quantitative PCR. As shown in Supplementary Figure S4C, the gene expression of PHD3 was not significantly affected by PHD2 knockdown.

\section{Discussion}

HIF is an important regulator of the cellular adaptation to hypoxia. In this study, we show that the oxygen sensor enzyme PHD2 regulates the HIF-dependent hypoxic adaptation of glioblastoma cells in a non-canonical way. PHD2 knockdown led to a significant downregulation of HIF- $1 \alpha$ expression and a marked reduction of $\mathrm{HIF}-1 \alpha$ protein in glioblastoma cells. A stabilization of HIF- $1 \alpha$ protein in the PHD2 knockdown cells could not be observed. As HIF-1 $\alpha$ protein is inducible by acute hypoxia in the glioblastoma cells, we assume that either PHD2 does not mediate the oxygendependent degradation of HIF- $1 \alpha$ or the PHD2-mediated HIF- $1 \alpha$-degradation is only of importance during acute hypoxic exposures.

The downregulation of HIF- $1 \alpha$ expression in the PHD2 knockdown cells was presumably caused by the decrease of $\mathrm{NF} \kappa \mathrm{B}$ basal activity. The interaction between PHD2 and the components of $\mathrm{NF} \kappa \mathrm{B}$ pathway has already been observed in several other tumor cell lines. ${ }^{15,16,19}$ In the osteosarcoma cell line LM8, PHD2 knockdown also caused a reduction of the basal $\mathrm{NF} \kappa \mathrm{B}$ activity due to the suppressed expression of $\mathrm{I}_{\kappa} \mathrm{B}$ kinase $\beta(\mathrm{IKK} \beta) .{ }^{19}$ In the colon carcinoma cell line HCT116 and the cervix carcinoma cell line HeLa, PHD2 was reported to decrease the basal activity of $\mathrm{NF} \kappa \mathrm{B} .{ }^{15,16}$ These findings suggest that the regulation of $\mathrm{NF} \kappa \mathrm{B}$ activity by PHD2 is highly cell type specific. In the glioblastoma cells, we could show that PHD2 maintains the basal $\mathrm{NF}_{\kappa} \mathrm{B}$ activity by positively regulating the gene expression of the $\mathrm{NF} \kappa \mathrm{B}$ subunit $\mathrm{p} 50$. As the regulation of p50 gene expression in glioblastoma cells is still unclear, the mechanisms by which PHD2 maintains the p50 expression remains to be further studied. In several other cell lines, the gene expression of p50 was shown to be influenced by factors such as human immunodeficiency virus, tumor necrosis factor- $\alpha$, platelet-activating factor and $\mathrm{N}$-Myc. ${ }^{35-37}$ p50 was also discussed to participate in its own regulation. ${ }^{35,38}$ It has not been confirmed that the autoregulatory feedback loop of p50 gene expression exists in glioblastoma cells. As the subcellular distribution of p50 was almost not affected by PHD2, it is rather unlikely that PHD2 regulates the gene expression of $\mathrm{p} 50$ by interacting with the upstream components of $\mathrm{NF} \kappa \mathrm{B}$ pathway like $\mathrm{I}_{\kappa} \mathrm{B} \alpha$ and IKK. Additional studies need to be performed to understand the interaction between $\mathrm{PHD} 2$ and $\mathrm{NF}_{\kappa} \mathrm{B}$ pathway in glioblastoma cells.

Although PHD2 was also shown to maintain the basal activity of $\mathrm{NF} \kappa \mathrm{B}$ in the LM8 cells, the steady-state levels of HIF- $1 \alpha$ was not reduced in the PHD2 knockdown LM8 cells. ${ }^{19}$ This suggests that in the LM 8 cells, the protein level of HIF- $1 \alpha$ is predominantly regulated by the PHD2/VHL axis, whereas the steady-state level of HIF- $1 \alpha$ in the glioblastoma cells is decisively dependent on the transcription rate of HIF- $1 \alpha$ gene. Besides, we cannot exclude the possibility that PHD2 might maintain the gene expression of HIF-1 $\alpha$ through other mechanisms in glioblastoma cells.

HIF-2 $\alpha$ is another important member of the HIF family of transcription factors. Although HIF- $1 \alpha$ and HIF- $2 \alpha$ share some overlapping functions, they also exhibit unique activities by regulating different target genes. ${ }^{39}$ In the PHD2 knockdown glioblastoma cells, the mRNA and protein levels of HIF- $2 \alpha$ were increased. Knockdown studies showed that the expression of HIF-2 $\alpha$ in glioblastoma cells is constitutively suppressed by HIF-1 $\alpha$ even under normoxic conditions. Therefore, we assume that the increase in HIF-2 $\alpha$ expression was caused by the downregulation of HIF- $1 \alpha$ expression. Although $\mathrm{NF} \kappa \mathrm{B}$ was also reported to promote HIF-2 $\alpha$ expression, the expression level of HIF-2 $\alpha$ seems to be solely influenced by the NF $\kappa$ B subunit p65. ${ }^{40}$ However, as little is 


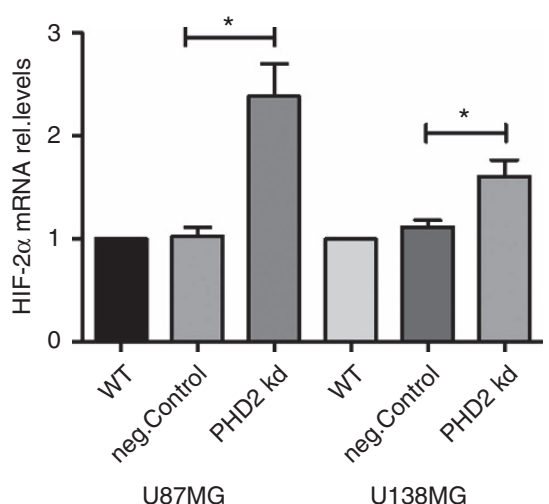

b

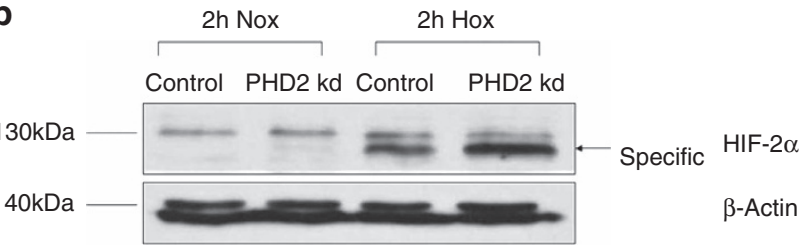

Figure 4 PHD2 enhances the gene expression of HIF-2 $\alpha$. (a) U87MG and U138MG cells were transfected with water (WT), non-specific siRNA (neg.Control) or siRNA against PHD2 (PHD2 kd). Forty-eight to seventy-two hours after transfection, total mRNA was analyzed for HIF-2 $\alpha$ and ribosomal protein L28 expression by qRT-PCR. Normalized HIF-2 $\alpha /$ L28 ratios are shown. The data are shown as the mean \pm S.E.M. $(n=3-6)$. ${ }^{*} P<0.05$. (b) U87MG cells were transfected with non-specific siRNA (Control) or siRNA against PHD2 (PHD2 kd). Forty-eight hours after transfection, cells were incubated for $2 \mathrm{~h}$ in normoxia or hypoxia $\left(3 \% \mathrm{O}_{2}\right)$. HIF- $2 \alpha$ was detected by immunoblotting. $\beta$-Actin was used as loading control. The results are representative for three independent experiments known about the regulation of HIF- $2 \alpha$ expression, we cannot exclude the possibility that PHD2 suppresses the HIF- $2 \alpha$ gene expression through other transcription factors or signaling molecules.

The expression of GLUT1 and VEGF-A was reported to be regulated by both HIF- $1 \alpha$ and HIF- $2 \alpha$. The mRNA levels of GLUT1 and VEGF-A were significantly elevated in the PHD2 knockdown glioblastoma cells incubated in hypoxia. Although HIF- $1 \alpha$ and HIF- $2 \alpha$ are both indispensable for maintaining the expression of GLUT1 and VEGF-A, it seems that when PHD2 is inhibited with siRNA, the loss of HIF- $1 \alpha$ is fully compensated by the upregulation of the HIF- $2 \alpha$ expression. The expression of hexokinase 2 (HK2) and phosphofructokinase (PFK), the pacemaker enzymes of glycolysis, was not affected in the PHD2 knockdown cells (Supplementary Figure S5), suggesting that PHD2 suppresses the glucose uptake of hypoxic glioblastoma cells without changing the rate of glycolysis. Although HIF-1 $\alpha$ was shown to promote the gene expression of glycolytic enzymes in several cell lines, ${ }^{41}$ the expression levels of HK2 and PFK in glioblastoma cells correlate neither with the oxygen concentration nor with the protein levels of $\mathrm{HIF}-1 \alpha$ (data not shown), which indicates that the genes of these enzymes are not targeted by HIF-1 $\alpha$ in glioblastoma cells.

The expression of BNIP3 was reported to be promoted specifically by HIF- $1 \alpha$. HIF- $2 \alpha$ was shown to suppress BNIP3 expression in renal carcinoma and hepatocellular carcinoma cells. $^{26,42}$ PHD2 knockdown caused a downregulation of BNIP3 expression in hypoxic glioblastoma cells. Although BNIP3 is known as an important mediator of hypoxia-induced
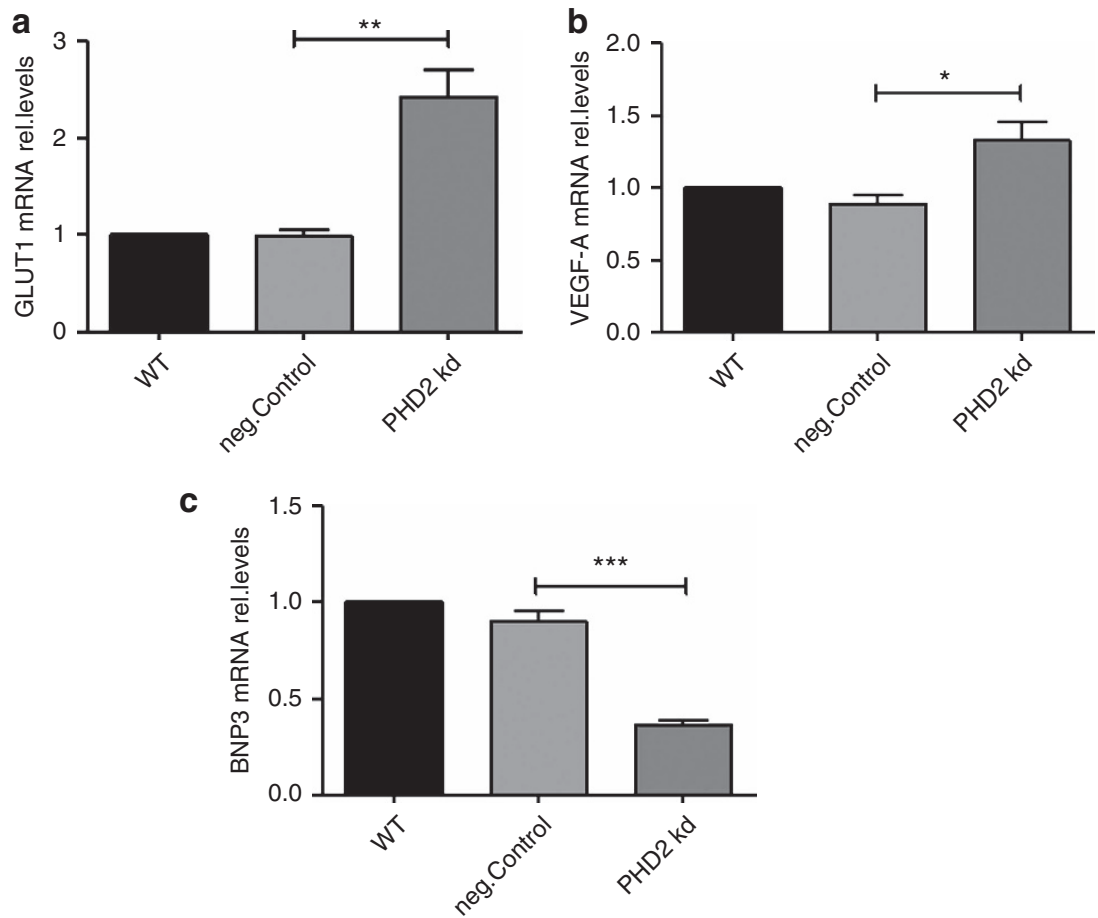

Figure 5 PHD2 modulates the expression of HIF target genes. (a-c): U87MG cells were transfected with water (WT), non-specific siRNA (neg.Control) or siRNA against PHD2 (PHD2 kd). Forty-eight hours after transfection, cells were incubated for $24 \mathrm{~h}$ in hypoxia $\left(3 \% \mathrm{O}_{2}\right)$. Total mRNA was analyzed for GLUT1, VEGF-A, BNIP3 and ribosomal protein L28 expression by qRT-PCR. Normalized GLUT1/L28 (a) VEGF-A/L28 (b) BNIP3/L28 (c) ratios are shown. The ratios were normalized to WT. The data are shown as the mean \pm S.E.M. $(n=3) .{ }^{*} P<0.05,{ }^{* *} P<0.01,{ }^{* *} P<0.001$ 
a

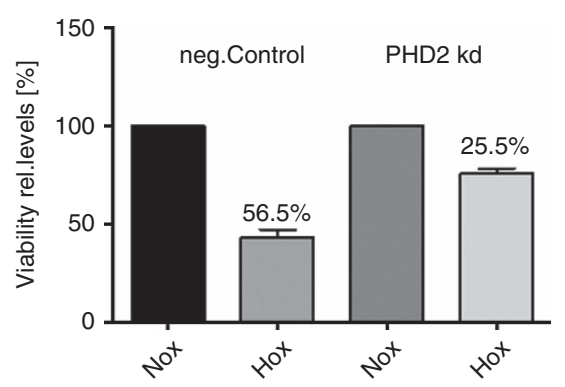

U138MG

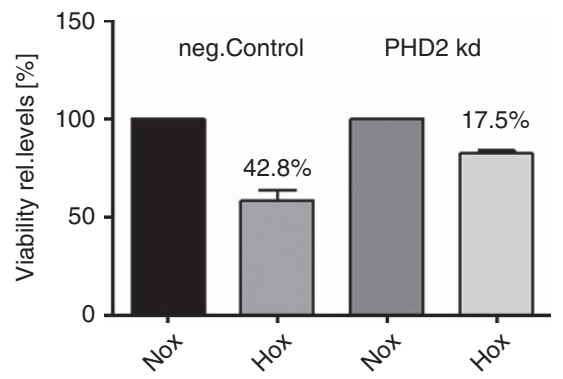

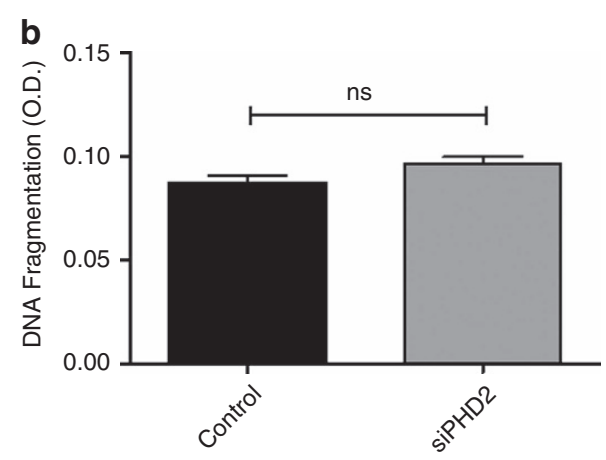

Figure 6 PHD2 modulates the survival of glioblastoma cells in hypoxia. (a) U87MG and U138MG cells were transfected with non-specific siRNA (neg.Control) or siRNA against PHD2 (PHD2 kd). Forty-eight hours after transfection, cells were incubated for $48 \mathrm{~h}$ in normoxia or hypoxia $\left(3 \% \mathrm{O}_{2}\right)$. Cell viability was determined by MTT assay. The data are shown as the mean \pm S.E.M $(n=3)$. (b) U87MG cells were transfected with non-specific siRNA (Control) or siRNA against PHD2 (siPHD2). Forty-eight hours after transfection, cells were incubated for $24 \mathrm{~h}$ in hypoxia $\left(3 \% \mathrm{O}_{2}\right)$. The apoptosis was determined using DNA fragmentation ELISA. The data are shown as the mean \pm S.E.M. $(n=6)$. NS, not significant

a
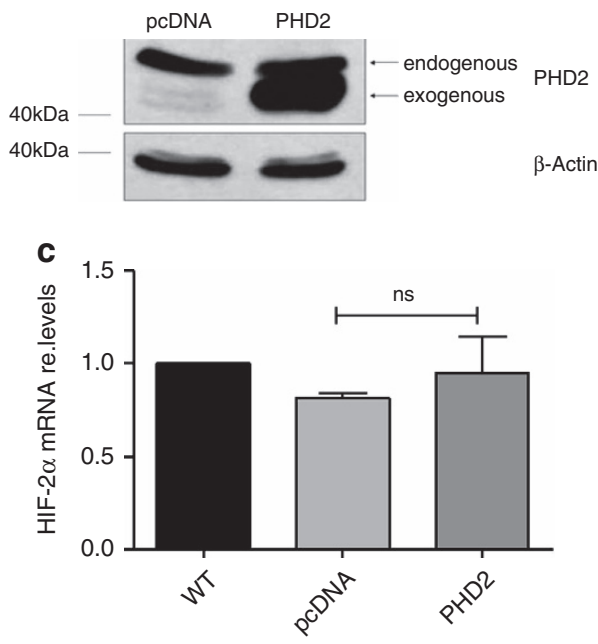

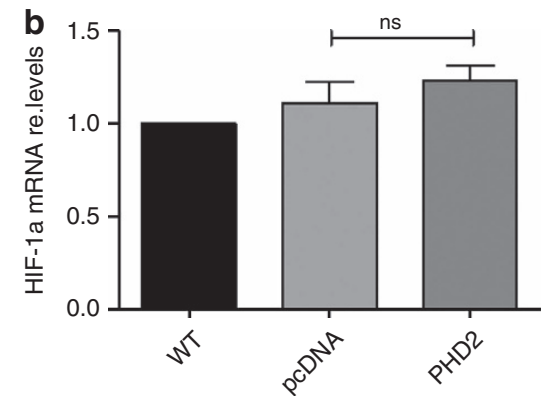

Figure 7 Exogenous PHD2 has no impact on the gene expression of HIF-1 $\alpha$ and HIF-2 $\alpha$. U87MG cells were transfected with empty vector (pcDNA) or PHD2 plasmid. (a) Twenty-four hours after transfection, PHD2 was detected by immunoblotting. $\beta$-Actin was used as loading control. The results are representative for three independent experiments. b, c: Forty-eight hours after transfection, total mRNA was analyzed for HIF-1 $\alpha$, HIF-2 $\alpha$ and ribosomal protein L28 expression by qRT-PCR. Normalized HIF-1 $\alpha /$ L28 (b) HIF-2 $\alpha /$ L28 (c) ratios are shown. The data are shown as the mean \pm S.E.M. $(n=3)$. NS, not significant

cell death, ${ }^{29}$ it was also discussed to inhibit temozolomideand ceramide-induced glioma cell death. ${ }^{30,31}$ Therefore, the promoting effect of PHD2 on BNIP3 expression in glioblastoma cells is probably not beneficial in all cases. The application of other therapeutic agents should be taken into consideration.
PHD2 knockdown further resulted in a reduction of hypoxiainduced glioblastoma cell death, presumably due to the modulated expression of GLUT1, VEGF-A and BNIP3. As the cells were incubated in absence of FCS to reduce proliferation, we cannot exclude the possibility that PHD2 might promote the proliferation of glioblastoma cells despite 
its potential to enhance hypoxia-induced glioblastoma cell death.

Hypoxia induces both necrosis and programmed cell death. $^{43}$ DNA fragmentation ELISA showed that the apoptosis of hypoxic glioblastoma cells is not influenced by PHD2. We assume the PHD2 promotes hypoxia-induced necrotic cell death and other forms of programmed cell death (such as autophagy and necroptosis), but not apoptotic cell death.

According to Evans et al., ${ }^{3}$ the hypoxia degrees in glioblastomas are in majority of cases moderate $\left(10\right.$ to $\left.0.5 \% \mathrm{O}_{2}\right)$. To simulate the in vivo situation, all hypoxic experiments were performed in $3 \% \mathrm{O}_{2}$.

Interestingly, overexpressed PHD2 has no influence on the expression of HIF- $1 \alpha$ and HIF- $2 \alpha$ in glioblastoma cells. We assume that exogenous PHD2 might not be fully biologically active. As we have not characterized the PHD2 substrate that is responsible for the non-canonical regulation of $\mathrm{HIF}-\alpha$, we were not able to compare the enzymatic activities of exogenous and endogenous PHD2 toward this specific substrate. Moreover, we have to consider the possibility that the sequences of endogenous and exogenous PHD2 differ from each other. Additional studies have to be performed.

In conclusion, the oxygen sensor PHD2 enhances hypoxiainduced glioblastoma cell death by regulating the gene expression of HIF- $1 \alpha$ and HIF- $2 \alpha$. The PHD2-mediated proteasomal degradation of $\mathrm{HIF}-1 \alpha$ and $\mathrm{HIF}-2 \alpha$ seems to have a minor role. PHD2 represents a potential prognostic marker and therapeutic target for glioblastomas with severe hypoxia. As overexpressed PHD2 has no influence on the gene expression of HIF- $1 \alpha$ and HIF- $2 \alpha$, it is necessary to find other ways to enhance the effect of endogenous PHD2 on glioblastoma cell death. Characterization of the interaction partners of $\mathrm{PHD} 2$ in $\mathrm{NF}_{\kappa} \mathrm{B}$ pathway, the possible genetic abnormalities of PHD2 and the mechanisms by which HIF-1 $\alpha$ suppresses HIF-2 $\alpha$ gene expression in glioblastoma cells would be obligatory.

\section{Materials and Methods}

Cell culture. The human glioblastoma cell lines U87MG and U138MG were obtained from the American Type Culture Collection. The human glioblastoma cell line U343MG was obtained from Cell Line Service (Eppelheim, Germany). Cells were cultured in DMEM (Gibco, Darmstadt, Germany) supplemented with 10\% FCS (Gibco), $100 \mathrm{IU} / \mathrm{ml}$ penicillin and $100 \mu \mathrm{g} / \mathrm{ml}$ streptomycin (PAA Laboratories, Coelbe, Germany) in a humidified atmosphere with $5 \% \mathrm{CO}_{2}$. For hypoxic treatments, cells were incubated in the presence of $3 \% \mathrm{O}_{2}, 5 \% \mathrm{CO}_{2}$ and $94 \% \mathrm{~N}_{2}$ at $37^{\circ} \mathrm{C}$.

MTT assay. The cell viability was determined using the MTT (Sigma-Aldrich, Seelze, Germany) assay. Cells were incubated with MTT solution $(5 \mathrm{~g} / \mathrm{l})$ for $2 \mathrm{~h}$ at $37^{\circ} \mathrm{C}$ and then lysed with MTT lysis buffer (10\% SDS, $1 \% \mathrm{HCl}, 0.46 \%$ isopropanol). The optical density was detected with a microplate reader (Thermo Scientific, Bonn, Germany) at $570 \mathrm{~nm}$.

Protein extraction. For the preparation of whole cell extracts, cells were washed with ice-cold PBS and lysed with urea lysis buffer containing $10 \mathrm{mM}$ Tris $\mathrm{HCl}(\mathrm{pH} 6.8), 7.6 \mathrm{M}$ urea, $10 \mathrm{M}$ glycerin, $1 \%$ SDS, $5 \mathrm{mM}$ DTT and protease inhibitor cocktail (Calbiochem, Darmstadt, Germany) or cell lysis buffer containing $300 \mathrm{mM} \mathrm{NaCl}, 10 \mathrm{mM}$ Tris (pH 7.9), $1 \mathrm{mM}$ EDTA, 0.1\% IGEPAL and protease inhibitor cocktail (Calbiochem). Protein concentrations were determined by Bio-Rad protein assay (Bio-Rad, Munich, Germany) using bovine serum albumin as the standard.
Immunoblot analysis. For immunoblot analysis, $30-60 \mu \mathrm{g}$ protein was subjected to 7.5 or $12 \%$ SDS-PAGE and transferred onto nitrocellulose membranes (Amersham Hybond-ECL, GE Healthcare, Freiburg, Germany). Membranes were blocked at room temperature for $1 \mathrm{~h}$ in $3 \%$ nonfat dry milk in PBS and then incubated with primary antibodies at room temperature for $2 \mathrm{~h}$. The following antibodies were used: mouse monoclonal antibodies against HIF-1 $\alpha$ (1:1000, BD Biosciences, Heidelberg, Germany), $\beta$-actin (1:5000, Applied Biological Materials, Richmond, British Columbia, Canada), $\alpha$-Tubulin ( $1: 1000$, Santa Cruz, Heidelberg, Germany), rabbit polyclonal antibodies against HIF-2 $\alpha$ (1:1000, GeneTex, Irvine, CA, USA), p50 (1:1000, Santa Cruz), PHD2 (1:500, Novus NB100-137, Cambridge, UK) and histone H1.4 (1:1000, Sigma-Aldrich), goat polyclonal antibody against Lamin A/C (1:1000, Santa Cruz). After being washed with PBS-T, membranes were incubated with horseradish peroxidase-conjugated anti-mouse, anti-rabbit or anti-goat immunoglobulin $G$ antibodies (1:2000, Dako, Hamburg, Germany). Immunoreactive proteins were detected using ECL detection reagents (Amersham ECL Western Blotting Detection Reagents, GE Healthcare) and X-ray films (Amersham Hyperfilm MP, GE Healthcare).

RNA isolation and quantitative RT-PCR. Total RNA was extracted using the 6100 Nucleic Acid Prepstation (Applied Biosystems, Darmstadt, Germany) following the manufacturer's instruction. Total RNA (200-500 ng) was reverse transcribed with SuperScript II Reverse Transcriptase (Invitrogen, Darmstadt, Germany) or SuperScript III Reverse Transcriptase (Invitrogen) according to the manufacturer's instructions. Quantitative RT-PCR was performed in $\mathrm{ABI}$ Prism 7000 Sequence Detection System (Applied Biosystems) using SensiMix SYBR Kit (Bioline, Luckenwalde, Germany) or Taqman Gene Expression Assay (Applied Biosystems). The mRNA levels were normalized to human L28 mRNA. The following primers and assays were used: human GLUT1 forward, 5'-GGC CTT TTC GTT AAC CGC TT-3'; human GLUT1 reverse, 5'-AGC ATC TCA AAG GAC TTG CCC-3'; human L28 forward, 5'-ATG GTC GTG CGG AAC TGC T-3'; human L28 reverse, 5'-TTG TAG CGG AAG GAA TTG CG-3'; human VEGF-A forward, 5'-GCA GAA TCA TCA CGA AGT GG-3'; human VEGF-A reverse, 5'-GCA TGG TGA TGT TGG ACT CC-3'; Taqman Gene Expression Assay for HIF-1 $\alpha$ (Hs00936368_m1), HIF-2 $\alpha$ (Hs01026149_m1), BNIP3 (Hs00969293_mH), p50 (Hs00765730_m1).

RNA interference. Cells were cultured to $60-70 \%$ confluence and transfected with $30 \mathrm{nM}$ siRNA or BLOCK-iT Fluorescent Oligo (Invitrogen) as negative control using Lipofectamine RNAiMAX (Invitrogen) according to the manufacturer's instruction. siRNA against HIF-1 $\alpha$ (Invitrogen) and PHD2 (Dharmacon, Darmstadt, Germany) were used.

Transfection of plasmid DNA. Cells were cultured to $70-90 \%$ confluence and transfected with plasmid DNA using Lipofectamine 2000 (Invitrogen) following the manufacturer's instruction.

Reporter gene assay. Cells were cultured to $60 \%$ confluence and cotransfected with a firefly luciferase plasmid containing five copies of $\mathrm{NF} \kappa \mathrm{B}$ binding sites (Promega, Mannheim, Germany) and a Renilla luciferase plasmid as transfection efficiency control. Cells were washed with ice-cold PBS and lysed with passive lysis buffer (Promega). Luminescence was measured with Mithras LB940 (Berthold Technologies, Bad Wildbad, Germany). Firefly luciferase activities were normalized to Renilla luciferase activities.

Detection of DNA fragmentation. Intracellular DNA fragmentation was detected using the Cellular DNA Fragmentation ELISA Kit (Roche Applied Science, Mannheim, Germany) following the manufacturer's instructions. The optical density was measured at $450 \mathrm{~nm}$ with a microplate reader (Thermo Scientific).

Statistical analysis. Data are shown as means \pm S.E.M. of at least three independent experiments. Statistical analysis between the two groups was performed by Student's $t$-test. Differences were considered significant when $P<0.05$ ( $\left.{ }^{\star} P<0.05 ;{ }^{* *} P<0.01,{ }^{* * *} P<0.001\right)$. All statistics were calculated using GraphPad Prism 5 (GraphPad Software, Witzenhausen, Germany).

\section{Conflict of Interest}

The authors declare no conflict of interest. 
Acknowledgements. We thank G Huck and P Rouina for excellent technical support. The project was supported by the University of Luebeck (P04-2012), Werner und Klara Kreitz-Stiftung and DFG Excellence Cluster Inflammation at Interfaces.

1. Wen PY, Kesari S. Malignant gliomas in adults. N Engl J Med 2009; 359: 492-507.

2. Rampling R, Cruickshank G, Lewis AD, Fitzsimmons SA, Workman P. Direct measurement of p02 distribution and bioreductive enzymes in human malignant brain tumors. Int $J$ Radiat Oncol Biol Phys 1994; 29: 427-431.

3. Evans SM, Judy KD, Dunphy I, Jenkins WT, Nelson PT, Collins R et al. Comparative measurements of hypoxia in human brain tumors using needle electrodes and EF5 binding. Cancer Res 2004; 64: 1886-1892.

4. Semenza GL. Regulation of oxygen homeostasis by hypoxia-inducible factor 1. Physiology (Bethesda) 2009; 24: 97-106.

5. Greer SN, Metcalf JL, Wang Y, Ohh M. The updated biology of hypoxia-inducible factor. EMBO J 2012; 31: 2448-2460.

6. Gordan JD, Simon MC. Hypoxia-inducible factors: central regulators of the tumor phenotype. Curr Opin Genet Dev 2007; 17: 71-77.

7. Scrideli CA, Carlotti CG Jr, Mata JF, Neder L, Machado HR, Oba-Sinjo SM et al. Prognostic significance of co-overexpression of the EGFR/IGFBP-2/HIF-2A genes in astrocytomas. $J$ Neurooncol 2007; 83: 233-239.

8. Schofield CJ, Ratcliffe PJ. Oxygen sensing by HIF hydroxylases. Nat Rev Mol Cell Biol 2004; 5: 343-354.

9. Oehme F, Ellinghaus P, Kolkhof P, Smith TJ, Ramakrishnan S, Hütter J et al. Overexpression of $\mathrm{PH}-4$, a novel putative proline 4-hydroxylase, modulates activity of hypoxia-inducible transcription factors. Biochem Biophys Res Commun 2002; 296: 343-349.

10. Koivunen $P$, Tiainen $P$, Hwärinen J, Williams KE, Sormunen R, Klaus SJ et al. An endoplasmic reticulum transmembrane prolyl 4-hydroxylase is induced by hypoxia and acts on hypoxia-inducible factor alpha. J Biol Chem 2007; 282: 30544-30552.

11. Henze AT, Riedel J, Diem T, Wenner J, Flamme I, Pouyseqqur J et al. Prolyl hydroxylase 2 and 3 act in gliomas as protective negative feedback regulators of hypoxia-inducible factors. Cancer Res 2010; 70: 357-366.

12. Kaelin WG. Proline hydroxylation and gene expression. Annu Rev Biochem 2005; 74: 115-128.

13. Berra E, Benizri E, Ginouves A, Volmat V, Roux D, Pouyssequr J. HIF prolyl-hydroxylase 2 is the key oxygen sensor setting low steady-state levels of HIF-1alpha in normoxia. EMBO J 2003; 22: 4082-4090.

14. Appelhoff RJ, Tian YM, Raval RR, Turley H, Harris AL, Pugh CW et al. Differential function of prolyl hydroxylases PHD1, PHD2, and PHD3 in the regulation of hypoxia-inducible factor. J Biol Chem 2004; 279: 38458-38465.

15. Cummins EP, Berra E, Comerford KM, Ginouves A, Fitzgerald KT, Seeballuck F et al. Prolyl hydroxylase-1 negatively regulates IkappaB kinase-beta, giving insight into hypoxiainduced NFkappaB activity. Proc Natl Acad Sci USA 2006; 103: 18154-18159.

16. Chan DA, Kawahara TL, Sutphin PD, Chang HY, Chi JT, Giaccia AJ. Tumor vasculature is regulated by PHD2-mediated angiogenesis and bone marrow-derived cell recruitment. Cancer Cell 2009; 15: 527-538.

17. Bordoli MR, Stiehl DP, Borsig L, Kristiansen G, Hausladen S, Schraml $P$ et al. Prolyl-4-hydroxylase PHD2- and hypoxia-inducible factor 2-dependent regulation of amphiregulin contributes to breast tumorigenesis. Oncogene 2011; 30: 548-560.

18. Wottawa M, Leisering P, Mv Ahlen, Schnelle M, Vogel S, Malz C et al. Knockdown of prolyl-4-hydroxylase domain 2 inhibits tumor growth of human breast cancer MDA-MB-231 cells by affecting TGF-beta1 processing. Int J Cancer 2013; 132: 2787-2798.

19. Klotzsche-von Ameln A, Muschter A, Mamlouk S, Kalucka J, Prade I, Franke K et al. Inhibition of HIF prolyl hydroxylase-2 blocks tumor growth in mice through the antiproliferative activity of TGFb. Cancer Res 2011; 71: 3306-3316.

20. Jaakkola PM, Rantanen $\mathrm{K}$. The regulation, localization, and functions of oxygen-sensing prolyl hydroxylase PHD3. Biol Chem 2013; 394: 449-457.

21. Klotzsche-von Ameln A, Prade I, Grosser M, Kettelhake A, Rezaei M, Chavakis T et al. PHD4 stimulates tumor angiogenesis in osteosarcoma cells via TGF-alpha. Mol Cancer Res 2013; 11: 1337-1348.

22. Rius J, Guma M, Schachtrup C, Akassoglou K, Zinkernagel AS, Nizet V et al. NF-kappaB links innate immunity to the hypoxic response through transcriptional regulation of HIF-1alpha. Nature 2008; 453: 807-811.

23. van Uden $\mathrm{P}$, Kenneth NS, Rocha $\mathrm{S}$. Regulation of hypoxia-inducible factor-1alpha by NF-kappaB. Biochem J 2008; 412: 477-484.

24. Belaiba RS, Bonello S, Zähringer C, Schmidt S, Hess J, Kietzmann T. Hypoxia up-regulates hypoxia-inducle factor-1alpha transcription by involving phosphatidylinositol 3-kinase and nuclear factor kappaB in pulmonary artery smooth muscle cell. Mol Biol Cell 2007; 18: 4691-4697.
25. Anelli V, Gault CR, Cheng AB, Obeid LM. Sphingosine kinase 1 is up-regulated during hypoxia in U87MG glioma cells. Role of hypoxia-inducible factor 1 and 2. J Biol Chem 2008: 283: 3365-3375.

26. Menrad H, Werno C, Schmid T, Copanaki E, Deller T, Dehne N et al. Roles of hypoxiainducible factor-1alpha (HIF-1alpha) versus HIF-2alpha in the survival of hepatocellular tumor spheroids. Hepatology 2010; 51: 2183-2192.

27. Flynn JR, Wang L, Gillespie DL, Stoddard GJ, Reid JK, Owens J et al. Hypoxia-regulated protein expression, patient characteristics, and preoperative imaging as predictors of survival in adults with glioblastoma multiforme. Cancer 2008; 113: 1032-1042.

28. Gillespie DL, Whang K, Ragel BT, Flynn JR, Kelly DA, Jensen RL. Silencing of hypoxia inducible factor-1alpha by RNA interference attenuates human glioma cell growth in vivo. Clin Cancer Res 2007: 13: 2441-2448.

29. Azad MB, Chen Y, Henson ES, Cizeau J, McMillan-Ward E, Israels SJ et al. Hypoxia induces autophagic cell death in apoptosis-competent cells through a mechanism involving BNIP3. Autophagy 2008; 4: 195-204.

30. Burton TR, Henson ES, Azad MB, Brown M, Eisenstat DD, Gibson SB. BNIP3 acts as transcriptional repressor of death receptor-5 expression and prevents TRAIL-induced cell death in gliomas. Cell Death Dis 2013; 4: e587.

31. Daido S, Kanzawa T, Yamamoto A, Takeuchi $\mathrm{H}$, Kondo $\mathrm{Y}$, Kondo S. Pivotal role of the cell death factor BNIP3 in ceramide-induced autophagic cell death in malignan glioma cells. Cancer Res 2004; 64: 4286-4293.

32. Gupta K, Kshirsagar S, Li W, Gui L, Ramakrishnan S, Gupta P et al. VEGF prevents apoptosis of human microvascular endothelial cells via opposing effects on MAPK/ERK and SAPK/JNK signaling. Exp Cell Res 1999; 247: 495-504.

33. Ge YL, Zhang X, Zhang JY, Hou L, Tian RH. The mechanisms on apoptosis by inhibiting VEGF expression in human breast cancer cells. Int Immunopharmacol 2009; 9: 389-395.

34. Narasimhan P, Liu J, Song YS, Massengale JL, Chan PH. VEGF stimulates the ERK1/2 signaling pathway and apoptosis in cerebral endothelial cells after ischemic conditions. Stroke 2009; 40: 1467-1473.

35. Paya CV, Ten RM, Bessia C, Alcami J, Hay RT, Virelizier JL. NF-kappa B-dependent induction of the NF-kappa B p50 subunit gene promoter underlies self-perpetuation of human immunodeficiency virus transcription in monocytic cells. Proc Natl Acad Sci USA 1992; 89: 7826-7830.

36. Tan X, Sun X, Gonzalez-Crussi FX, Gonzalez Crussi F, Hsueh W. PAF and TNF increase the precursor of NF-kappa B p50 mRNA in mouse intestine: quantitative analysis by competitive PCR. Biochim Biophys Acta 1994; 1215: 157-162.

37. van 't Veer LJ, Beijersbergen RL, Bernards R. N-myc suppresses major histocompatibility complex class I gene expression through down-regulation of the p50 subunit of NF-kappa B. EMBO J 1993; 12: 195-200.

38. Ten RM, Paya CV, Israel N, Le Bail O, Mattei MG, Virelizier JL et al. The characterization of the promoter of the gene encoding the p50 subunit of NF-kappa B indicates that it participates in its own regulation. EMBO J 1992; 11: 195-203.

39. Keith B, Johnson RS, Simon MC. HIF1alpha and HIF2alpha: sibling rivalry in hypoxic tumour growth and progression. Nat Rev Cancer 2011; 12: 9-22.

40. Saito T, Fukai A, Mabuchi A, Ikeda T, Yano F, Ohba S et al. Transcriptional regulation of endochondral ossification by HIF-2alpha during skeletal growth and osteoarthritis development. Nat Med 2010; 16: 678-686.

41. Yeung SJ, Pan J, Lee MH. Roles of p53, MYC and HIF-1 in regulating glycolysis-the seventh hallmark of cancer. Cell Mol Life Sci 2008; 65: 3981-3999.

42. Raval RR, Lau KW, Tran MG, Sowter HM, Mandriota SJ, Li JL et al. Contrasting properties of hypoxia-inducible factor 1 (HIF-1) and HIF-2 in von Hippel-Lindau-associated renal cell carcinoma. Mol Cell Biol 2005; 25: 5675-5686.

43. Shimizu S, Equchi Y, Kamiike W, Itoh Y, Haseqawa J, Yamabe K et al. Induction of apoptosis as well as necrosis by hypoxia and predominant prevention of apoptosis by $\mathrm{Bcl}-2$ and BCl-XL. Cancer Res 1996; 56: 2161-2166.

(i) (1) $)$ Cell Death and Disease is an open-access journal published by Nature Publishing Group. This work is licensed under a Creative Commons Attribution-NonCommercialNoDerivs 3.0 Unported License. The images or other third party material in this article are included in the article's Creative Commons license, unless indicated otherwise in the credit line; if the material is not included under the Creative Commons license, users will need to obtain permission from the license holder to reproduce the material. To view a copy of this license, visit http://creativecommons.org/licenses/ by-nc-nd/3.0/ 